\title{
Correcting Sea Surface Temperature Spurious Effects in Salinity Retrieved From Spaceborne L-Band Radiometer Measurements
}

\author{
Boutin Jacqueline ${ }^{1,{ }^{*}}$, Vergely Jean-Luc ${ }^{2}$, Dinnat Emmanuel P. ${ }^{3}$, Waldteufel Philippe ${ }^{4}$, \\ D'Amico Francesco ${ }^{5}$, Reul Nicolas ${ }^{6}$, Supply Alexandre ${ }^{7}$, Thouvenin-Masson Clovis ${ }^{7}$
}

${ }^{1}$ Laboratoire d'Océanographie et du Climat: Expérimentations et Approches Numériques-Institut Pierre Simon Laplace (LOCEAN-IPSL), Sorbonne Université, CNRS, IRD, MNHN, 75005 Paris, France

2 ACRI-st, 78280 Guyancourt, France.

${ }^{3}$ Cryospheric Sciences Laboratory, NASA Goddard Space Flight Center, Greenbelt, MD 20771 USA.

${ }^{4}$ Cryospheric Sciences Laboratory, NASA Goddard Space Flight Center, Greenbelt, MD 20771 USA.

${ }^{5}$ Argans, Plymouth PL6 8BU, U.K..

${ }^{6}$ Laboratoire d'Océanographie Physique et Spatial (LOPS), Institut Français de Recherche pour I'Exploitation de la Mer (IFREMER), CNRS, IRD, Université de Bretagne Occidentale, 29238 Brest, France.

7 LOCEAN-IPSL, Sorbonne Université, CNRS, IRD, MNHN, 75005 Paris, France.

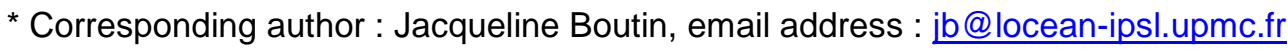

\begin{abstract}
:
Earlier studies have pointed out systematic differences between sea surface salinity retrieved from Lband radiometric measurements and measured in situ, which depend on sea surface temperature (SST). We investigate how to cope with these differences given existing physically based radiative transfer models. In order to study differences coming from seawater dielectric constant parametrization, we consider the model of Somaraju and Trumpf (2006) (ST) which is built on sound physical bases and close to a single relaxation term Debye equation. While ST model uses fewer empirically adjusted parameters than other dielectric constant models currently used in salinity retrievals, ST dielectric constants are found close to those obtained using the Meissner and Wentz (2012) (MW) model. The ST parametrization is then slightly modified in order to achieve a better fit with seawater dielectric constant inferred from SMOS data. Upgraded dielectric constant model is intermediate between KS and MW models. Systematic differences between SMOS and in situ salinity are reduced to less than $+/-0.2$ above $0{ }^{\circ} \mathrm{C}$ and within $+/-$ 0.05 between $7{ }^{\circ} \mathrm{C}$ and $28^{\circ} \mathrm{C}$. Aquarius salinity becomes closer to in situ salinity, and within $+/-0.1$. The order of magnitude of remaining differences is very similar to the one achieved with the Aquarius version 5 empirical adjustment of wind model SST dependence. The upgraded parametrization is recommended for use in processing the SMOS data. Further assessment or improvement using new laboratory measurements should consider keeping the physics-based formulation by ST that has been shown here to be very efficient.
\end{abstract}

Keywords : Dielectric constant, L-band microwave radiometry, sea surface salinity (SSS). 


\section{INTRODUCTION}

It is possible to measure Sea Surface Salinity (SSS) from space using L-band $(1.4 \mathrm{GHz})$ radiometric measurements, owing to the sensitivity of the sea surface emissivity at that frequency to salinity. Indeed, sea surface emissivity depends on the dielectric constant of sea water, which, in turn, depends on salinity and temperature for low microwave frequencies. Taking advantage of this property, SSS has been successfully retrieved from space since 2010 through L-band radiometer measurements onboard the SMOS, Aquarius and SMAP satellite missions (see reviews of scientific achievements in Reul et al. [1] and Vinogradova et al. [2]). Nevertheless, given the weak sensitivity of L-band brightness temperatures (Tb) to SSS (from $~ 0.7$ K.pss ${ }^{-1}$ in warm waters to $0.2 \mathrm{~K} . \mathrm{pss}^{-1}$ in cold waters for a nadir view), the accuracy of the retrieved SSS critically depends on the accuracy of radiometric measurements and on the quality of the Radiative Transfer Model (RTM) of the contributions to L-band Tb. Key components of the RTM include the dependency of sea surface emissivity upon Sea Surface Temperature (SST), SSS, roughness and foam, as well as atmospheric emission and absorption, celestial and solar signal scattered by the sea surface towards the radiometer and finally ionospheric Faraday rotation. Dinnat et al. [3] found that the different SST dependencies between SMOS and Aquarius SSS residuals with respect to in situ reference SSS data are explainable by the use of different modelling options (their Figure 16). They show that while using the Millimeter-wave Propagation Model (MPM) 92 [4] atmospheric model significantly reduces the differences, SSS residuals strongly depend on the dielectric constant model (Figure 1). 
Current Aquarius and SMAP processing use empirical SST adjustments of the wind induced emissivity to correct for SST dependent systematic errors [5]. These adjustments were fitted to Aquarius and SMAP measurements. They may not be optimal in the SMOS case, since SMOS samples a broader range of incidence angles, between nadir and $60^{\circ}$, not sampled by Aquarius and SMAP. Given that the SMOS processing uses a two-scale roughness emissivity model that includes a physically based SST dependency (Fig. 7 in [6]), the objective of the present study is to explore alternative corrections for the SST dependent systematic errors, and to propose corrective approaches to efficiently reduce them.

The investigation is carried out based on SMOS observations and the results are validated using Aquarius SSS data retrieved using various RTM components.

We present Data and Methods in section II, Results in section III, a discussion in sections IV and a conclusion in section V.

\section{DATA AND METHODS}

\section{A. SMOS standard processing}

The SMOS Tb at the top of the atmosphere is modelled in the level 2 ocean salinity processor (L2OS) as described in [7]: $T b=\left[\left(T b_{\text {flat }}+T b_{\text {rough }}\right)(1-F)+F T b_{\text {foam }}+T b_{D N} \Gamma+T b_{\text {gal }}\right] e^{-\tau_{\text {atm }}}+$ $T b_{U P}$

Where $T b_{\text {flat }}$ is the flat sea $\mathrm{Tb}, T b_{\text {rough }}$ is the contribution of the sea surface roughness, $F$ is the fraction of the sea surface covered by foam, $T b_{\text {foam }}$ is the contribution due to the foam emissivity, $T b_{D N}$ is the downward emitted atmospheric radiation, $\Gamma$ is the sea surface reflection coefficient, $T b_{g a l}$ is the contribution of the cosmic and galactic signals scattered by the sea surface, $T b_{U P}$ is the atmospheric self-emission directed to the antenna and $e^{-\tau_{a t m}}$ is the atmospheric attenuation. For simplicity, in the above equation, we neglect the Faraday rotation (a Faraday rotation is applied in the SMOS data processing used in the following).

We detail below the components of the forward model (1) involving sea surface emissivity:

- $T b_{\text {flat }}$ is related to the dielectric constant of sea water, $\varepsilon$, through the power Fresnel reflection coefficients, R:

$$
\begin{gathered}
T b_{\text {flat }}=(1-R) \cdot S S T \\
R_{v}=\left|\frac{\varepsilon \cos (\theta)-\sqrt{\varepsilon-\sin ^{2}(\theta)}}{\varepsilon \cos (\theta)+\sqrt{\varepsilon-\sin ^{2}(\theta)}}\right|^{2} \\
R_{h}=\left|\frac{\cos (\theta)-\sqrt{\varepsilon-\sin ^{2}(\theta)}}{\cos (\theta)+\sqrt{\varepsilon-\sin ^{2}(\theta)}}\right|^{2}
\end{gathered}
$$

With $\theta$ the incidence angle, $v$ and $h$ indices indicating vertical and horizontal polarisation. In the SMOS L2OS algorithm, the complex sea water dielectric constant $\varepsilon$ is modelled following the Klein and Swift [8] formulation (KS hereafter); see section C.

- $T b_{\text {rough }}$ is simulated using a two-scale model [9] [6] with a wave spectrum revisited by Yin $e t$ al. [10]. The sea surface state is described by the wave spectrum of Durden and Vesecki [11] multiplied by a factor 1.25 adjusted with SMOS observations. The small-wave scattering by the sea surface is modelled using a small slope approximation model for the bistatic scattering coefficients at L-band. The model slightly depends on the SST due to the ocean surface inclination by the large-scale waves leading to a R- $\theta$ dependency and to the dependence of bistatic coefficients on SST (Figure 2).

- F and $T b_{\text {foam }}$ are related to wind speed according to models described in Yin et al. [10].

Our study is restricted to the 5 to $9 \mathrm{~m} \cdot \mathrm{s}^{-1}$ moderate wind speed range, for which the forward models for $T b_{\text {rough }}, F$ and $T b_{\text {foam }}$ are known to be the most accurate.

-The atmospheric contribution is modelled using MPM 93 [12] parametrizations, simplified by assuming standard vertical temperature profiles that depend only on surface atmospheric parameters, as described in the SMOS ATBD [13].

- A vicarious calibration of SMOS Tb is performed using the so-called Ocean Target Transformation (OTT) correction [14], in which a mean correction at each point in the SMOS field of view is derived from the difference between modelled and observed $\mathrm{Tb}$ averaged over a large area in the southern Pacific Ocean. Given the sensitivity of Tb to SSS and SST [15], the observed bias on SSS (Figure 1) cannot be explained by a bias in the OTT (a $0.2 \mathrm{~K}$ bias in the OTT would generate a SSS bias of 0.8 at $0^{\circ} \mathrm{C}, 0.5$ at $10^{\circ} \mathrm{C}$ and 0.3 at $30^{\circ} \mathrm{C}$ which differs from the SST dependency observed in Figure 1).

We now describe the data sets and methodologies involved for analyzing SMOS and Aquarius data and for interpreting the results.

\section{B. SMOS pseudo-dielectric constant analysis}

\section{1) The Acard quantity derived from SMOS data}

Waldteufel et al. [16] have assessed the information on the dielectric constant that can be extracted from multi-angular SMOS $\mathrm{Tb}$ measurements, independently of any salinity information. They found that the retrieval of both the real part, $\varepsilon^{\prime}$, and imaginary part, $\varepsilon "$, of the dielectric constant, $\varepsilon$, is an ill posed problem. Actually, the cost function (Chi2) of $\left(\varepsilon^{\prime}, \varepsilon^{\prime \prime}\right)$ retrieval exhibits a minimum valley rather than a single minimum. Nevertheless, this Chi2 valley can be used to analytically represent the link between $\varepsilon^{\prime}$ and $\varepsilon^{\prime \prime}$ and [16] have identified that a modified cardioid function, with a size parameter Acard, a polar angle, Ucard, and an offset, Bcard, is well suited for representing that link. One writes the real and imaginary parts as:

$\varepsilon^{\prime}=$ Acard $(1+\cos ($ Ucard $)) \cos ($ Ucard $)+$ Bcard

$\varepsilon^{\prime \prime}=$ Acard $(1+\cos ($ Ucard $)) \sin ($ Ucard $)$

which is equivalent to:

$$
\begin{aligned}
\text { Acard } & =m_{-} \text {card }{ }^{2} /\left(m_{-} \text {card }+\varepsilon^{\prime}-\text { Bcard }\right) \\
\text { Ucard } & =\tan ^{-1}\left(\varepsilon^{\prime \prime} /\left(\varepsilon^{\prime}-\text { Bcard }\right)\right) \\
\text { with: } m_{-} \text {card } & =\left(\left(\varepsilon^{\prime}-\text { Bcard }\right)^{2}+\varepsilon^{\prime \prime 2}\right)^{1 / 2}
\end{aligned}
$$

Bcard corresponds to the shift between the observed Chi2 valley (Figure 3 in [16]) and a true cardioid function that crosses the origins of axes $(0,0)$. According to [16], the optimal Bcard value that minimizes the retrieval error on Acard is equal to 0.8. For large values of Acard, as observed over the ocean, Acard dependence to Ucard was found negligible. 
Over ocean, Acard is close to the modulus of the dielectric constant and varies between about 40 and 65 (Figure 3, right column). A minimum of Chi2 is obtained for the same value of Acard for any value of the angle Ucard. Relationships (2) are valid only for the emission by a flat surface due to Fresnel reflection; it is therefore necessary to correct SMOS $\mathrm{Tb}$ measurements from other effects (i.e. surface roughness and foam contributions, galactic noise scattered by the ocean surface, atmospheric emission and absorption) to get $\mathrm{Tb}$ values corresponding to a flat surface emission before retrieving Acard. These corrections are performed using emissivity, scattering and radiative transfer models forced with auxiliary parameters (wind, SST and atmospheric parameters) obtained from the European Centre for Medium-Range Weather Forecasts (ECMWF) Integrated Forecasting System (IFS), and implemented in the ESA level 2 SMOS $v 662$ processor (https://earth.esa.int/web/guest/missions/esa-operational-eomissions/smos/news/-/article/smos-level-2-sea-surface-

salinity-products-v662-released-to-users). The Acard retrieval is performed using an iterative Levenberg and Marquard's algorithm [17]. Minimization of the weighted differences between measured and modelled Tbs at the antenna level is performed using the following cost function:

$$
\operatorname{chi2}(P 1, P 2)=\sum_{i=0}^{N m-1} \frac{\left[T_{b i}^{\text {meas }}-T_{b i}^{\text {mod }}\left(\theta_{i} P 1, P 2\right)\right]^{2}}{\sigma_{T_{b i}}{ }^{2}}+\sum_{P=P 1, P 2} \frac{\left[P^{\text {prior }}-P^{\text {ret }}\right]^{2}}{\sigma_{P}{ }^{2}}
$$

where (P1, P2) are (Acard, SST), Nm is the number of multiangular $\mathrm{Tb}$ samples considered for the Acard and SST retrievals, $T_{b_{i}}^{\text {meas }}$ and $T_{b_{i}}^{\text {mod }}$ are the radiometer and modelled $\mathrm{Tb}$, respectively, $\sigma_{T_{b_{i}}}$ are the SMOS radiometric errors (varying with the location of the retrieval point within the field of view of the instrument); $P^{\text {prior }}, P^{\text {ret }}$ and $\sigma_{P}$ are the a priori values, retrieved values, and a priori error on the $\mathrm{P} 1$ and $\mathrm{P} 2$ parameters, respectively. The Acard retrieval is carried out under very weak a priori constraints. The prior SST is thus set to ECMWF SST (see next section) with a $1^{\circ} \mathrm{C}$ uncertainty. Acard ${ }^{\text {prior }}$ is set to 1 , which is very far from typical ocean values and $\sigma_{\text {Acard }}$ is set to 50.

We consider the ensemble of SMOS retrievals performed over the period 2012-2015. The initial operation period (2010-2011) was discarded in order to both ensure that the instrument was fully stable, and avoid large spurious signals due to strong Radio Frequency Interferences (RFI) which occurred in the northern hemisphere during that time [18]. Furthermore, in order to select the most reliable SMOS retrievals, we keep only data:

-within +/-400 km away from the track, in order to avoid SMOS swath edges with fewer and noisier $\mathrm{Tb}$ measurements than in the central part of the swath,

-further than $1000 \mathrm{~km}$ away from the coasts, in order to avoid land-sea contamination [19],

-for ECMWF wind speeds between 5 and $9 \mathrm{~m} \mathrm{~s}^{-1}$, as discussed above,

-for latitudes south of $40^{\circ} \mathrm{N}$ (both ascending and descending orbits) in order to avoid high northern latitudes possibly contaminated by remaining RFI, ice vicinity and solar contamination during the eclipse period [19],

-for latitudes north of $60^{\circ} \mathrm{S}$ and $50^{\circ} \mathrm{S}$ for descending and ascending orbits, respectively. This latitudinal filtering helps to minimize ice-sea contamination which exhibits a distinct impact on the SMOS measurements in descending and ascending passes. Indeed, same as in the land-sea case, the contrast in emissivity between ice and ocean creates a contamination which depends on the orbit orientation relative to the ice edge. This contamination is especially important for SMOS ascending orbits in the Southern Ocean.

-In order to best detect and remove outliers in SMOS retrievals mostly linked to RFI, we do not consider SMOS retrieved Acard values that differ by more than 2 units from the reference Acard computed using the KS model, in situ SSS and ECMWF SST (see below).

\section{2) Sea Surface Temperature}

A priori SST values at SMOS retrieval points are provided by bilinear spatial interpolation of the ECMWF IFS SST given in the top layer $(1 \mathrm{~m})$ of the ocean model, 6 to 18 hours after the forecast initialization depending on SMOS retrieval points acquisition time [20]. The forecast is initialized with the Operational Sea Surface Temperature and Sea Ice Analysis (OSTIA) [21] foundation temperature obtained the day before. The SST temporal evolution is derived from the oceanatmosphere coupled model. In the conditions considered here (moderate wind speed, SMOS local time passes at 6AM and 6PM), the $\mathrm{Tb}$ variation associated to the SST diurnal variation (less than $0.1^{\circ} \mathrm{C}$, e.g. [22]) is expected to be negligible ( $\mathrm{Tb}$ variation less than $0.02 \mathrm{~K}$ at most temperatures and incidence angles); similarly, at these moderate wind speeds, the temperature difference between $1 \mathrm{~m}$ depth and the skin depth in L-Band radiometry $(1 \mathrm{~cm})$ is expected to be very small [23]. In the following, we assume a $0.6^{\circ} \mathrm{C}$ uncertainty on the ECMWF IFS SST, consistent with the uncertainty estimated for OSTIA SST products [21].

\section{3) In situ near surface salinity}

We consider in situ near surface salinity recorded with Thermosalinograph onboard ships as well as the upper ocean data collected from Argo floats over the global ocean.

Thermosalinograph salinity data from Sailing and Research ships are taken from the Global Ocean Surface Underway Data GOSUD (www.gosud.org) data base. Salinities from Voluntary Observing Ship are taken from the 'Observatoire de Recherche en Environnement' (ORE SSS). These data are quality controlled according to procedures described in [24] and [25] respectively. Only "good" or "probably good" data are retained for our analyses.

Argo upper salinity values are taken from the standardized profiles of [26] generated after a careful data quality control, keeping only "adjusted" salinities with quality ranging from "good" to "acceptable".

Daily maps of the SMOS measurements gridded on an EASE 2 grid [27] at a spatial resolution of $25 \mathrm{~km}$ were used to derive satellite/in situ match-up pairs as follows: at each grid point, both SMOS and in situ SSS are averaged in a box $25 \mathrm{~km}$ wide in latitude and $50 \mathrm{~km}$ wide in longitude, over a day long time interval. In order to reduce the SMOS-related noise, the paired data are next averaged over 10 days. SMOS retrieved Acard are then compared to direct estimates of Acard derived 
from various sea water dielectric constant models (equation 2) that use the paired values of co-localized in situ SSS and ECMWF SST as input.

\section{Dielectric constant models}

Historically, various sea water dielectric constant formulations applicable to the microwave bands have been proposed to relate $\varepsilon$ to sea surface parameters. At low microwave frequencies, for fresh water, the single Debye [28] relaxation law is the most commonly agreed physical description of the frequency dependency of the dielectric constant:

$$
\varepsilon=\varepsilon_{\infty}(T)+\frac{\left(\varepsilon_{S}(T)-\varepsilon_{\infty}(T)\right)}{1+i \omega \tau(T)}
$$

where $i$ is the imaginary unit, $T$ indicates temperature dependency, $\varepsilon_{\infty}$ is the dielectric constant at very high (infinite) frequency, $\varepsilon_{s}$ is the static (zero frequency) dielectric constant, $\tau$ is the relaxation time in seconds, $\omega$ is the angular frequency of oscillation of the electric field. (3a) assumes that the molecules are free and do not interact with each other and that the polarization of the dielectric consists of both induced and orientation components; more details are found in [29] and references therein. The induced component of polarization is assumed to have no inertia, and depends on the electrical permittivity at very high frequencies, $\varepsilon_{\infty}$, and on the permittivity of free space, $\varepsilon_{0}$. The orientation polarization rises exponentially, with a relaxation time $\tau$, and the maximum value of total polarization reachable for an infinite time is expressed as a function of a static dielectric constant, $\varepsilon_{\mathrm{s}}$. In the case of sea water, the effect of conductivity loss is added; most authors moreover propose to introduce salinity and temperature dependencies in $\varepsilon_{\mathrm{s}}, \varepsilon_{\infty}$ and $\tau$ that are adjusted empirically. Hence, at low frequencies, the dielectric constant of sea water is commonly expressed using a single Debye relaxation law (3a), with various dependencies on temperature and salinity (T,S), according to different authors (e.g. [8], [30], [31]; in fact, [30] and [31] have proposed a double Debye relaxation law, but the second relaxation term is negligible at L-Band):

$\varepsilon(\omega, T, S)=\varepsilon_{\infty}(T, S)+\frac{\varepsilon_{S}(T, S)-\varepsilon_{\infty}(T, S)}{(1+i \omega \tau(T, S))}-\frac{i \sigma(T, S)}{\varepsilon_{0} \omega}$

where $\omega$ is the angular frequency $\left(2 \pi 1.413510^{9} \mathrm{~Hz} \cdot \mathrm{rad}\right.$ in the case of SMOS), $\sigma$ is the ionic conductivity of the dissolved salts in sea water in siemens per meter, $\varepsilon_{0}$ is the permittivity of free space. However, as underlined by Somaraju and Trumpf [29] (ST hereafter), in this approach, the description of the dielectric constant dependencies with $\mathrm{S}$ and $\mathrm{T}$ lacks a physical basis and the $\mathrm{T}$ and $\mathrm{S}$ fits are poorly constrained. This led ST to propose a physically-based realistic model, similar to those used in plasma physics, to describe the temperature dependency of the dielectric constant of seawater for a range of frequencies and salinities. They describe the total polarization of sea water as the sum of two terms: $\mathrm{P}_{\mathrm{b}}$, the polarization due to the displacement of bound charges in water molecules (i.e. induced and orientation polarization) and $\mathrm{P}_{\mathrm{f}}$, the polarization due to the displacement of ions inside water (i.e. atomic polarization). For low microwave frequencies, their model for $\mathrm{P}_{\mathrm{f}}$ tends towards the expression given by the last term of equation ( $3 b)$, which was previously determined empirically. For estimating $\mathrm{P}_{\mathrm{b}}, \mathrm{ST}$ assume that the number of water molecules that orient themselves around the dissolved ions is simply proportional to the number of ions, $N i$. Hence $\varepsilon_{s}$ decreases linearly with $\mathrm{S}$. Since $N i$ is also considered too small to affect $\tau, \mathrm{P}_{\mathrm{b}}$ effect on the dielectric constant of sea water can be written simply by introducing in equation (3a) a multiplicative factor $(1-\alpha(T)$. $S$ ) in front of $\varepsilon_{S}(T)$. At low frequency, considering both $\mathrm{P}_{\mathrm{b}}$ and $\mathrm{P}_{\mathrm{f}}$, the dielectric constant of sea water finally reduces to a form very similar to $(3 \mathrm{~b})$ :

$$
\begin{aligned}
\varepsilon(T, S)= & \epsilon_{1}(T, S=0)+ \\
& \frac{\epsilon_{S}(T, S=0) \cdot(1-\alpha(T) \cdot S)-\epsilon_{1}(T, S=0)}{1+i \omega \tau(T, S=0)}-\frac{j \sigma(T, S)}{\omega \varepsilon_{0}}
\end{aligned}
$$

In order to adjust the static dielectric constant dependency with salinity, ST have used the freshwater parameters and $\sigma$ as defined in Stogryn et al. [32] and they have fitted $\alpha$ on a synthetic dataset in a frequency range of 1 to $256 \mathrm{GHz}$ for a few $T$ and $S$ values, using previous dielectric constant models ([32], [30], [33], and [34]). They could not find a significant dependency of $\alpha$ with $\mathrm{T}$ and came up with a constant value $\alpha=0.00314$. At L-Band, the dielectric constant model obtained with the ST parametrization and with the Meissner and Wentz [31] parametrization (MW hereafter) are very close over the oceanic SST range (Figure 3) and almost identical for fresh water (not shown). The freshwater parameters in [32] and [30] are indeed very similar. In our study, we select the physically based ST formulation (equation 4) and we derive an empirical model for $\alpha(T)$ based on a best match between Acard values retrieved from SMOS and expected from co-localized in situ SSS and ECMWF SST. The resulting dielectric constant parametrization is called $\mathrm{BV}$.

\section{Independent assessments}

In order to provide an independent assessment of the impact of using the BV parametrization instead of the KS model on SSS retrieved from L-band observations, we analyze two independent sets of salinities retrieved from Tbs processed with both KS and BV parametrizations, as described below.

\section{1) SMOS level 3 SSS from an updated version}

We take advantage of a SMOS level 1 ongoing experimental reprocessing (Level 1 version 722 scenario $8 \mathrm{C}$ ) in which SMOS $\mathrm{Tb}$ calibration and image reconstruction process have been updated. In order to avoid as much as possible ice-sea and land-sea contamination, and eclipse periods in the northern hemisphere, we only consider data on descending orbits between $45^{\circ} \mathrm{N}$ and $60^{\circ} \mathrm{S}$, further than $1000 \mathrm{~km}$ from coast, during the period March to October 2016. SMOS SSS are retrieved using either KS or BV dielectric constant, the other RTM components remaining the same. SMOS level 2 data are very noisy (SSS noise $\sim 1$ in cold waters). For developing the BV parametrization, we reduce this noise by averaging level 2 data in SST bins. However, most scientific studies use level 3 rather than level 2 SMOS SSS. Hence, we assess our correction using SMOS level 3 SSS. Monthly SMOS level 3 SSS maps are generated using the methodology described in [35], in which wind speed range $\left(3-12 \mathrm{~m} \mathrm{~s}^{-1}\right)$ is wider than the one considered in our previous analysis. They are compared with In-Situ Analysis System (ISAS) maps ([36]) derived from Argo and in situ SSS measurements in 
near real time. During March to October 2016, ISAS SSS are systematically saltier than the climatology used in the OTT computation, by 0.03 to 0.06 . A corresponding correction has been applied to SMOS SSS.

2) Aquarius analysis

The BV parametrization has also been applied to Aquarius measurements with forward models similar to those used for SMOS, following a procedure similar to the one described in [3]. We reprocess the Aquarius retrievals changing the dielectric constant model and the atmospheric correction. We proceed in the same way as in Dinnat et al. [3]'s study. The level 2 of the Aquarius version 3 (V3) nominal RTM was used as a starting point, because it does not include the empirical tuning (designed to mitigate SST-dependent biases in SSS) introduced since version 4 . With respect to SMOS 2-scale model, Aquarius V3 only takes into account a scaling effect computed for a flat sea. This effect is smaller than the one in SMOS wind model (Figure 2). In a first step, the Aquarius Tb are recalibrated using the new BV dielectric constant model before SSS retrievals are computed on the almost 4 years-long period of Aquarius data. Aquarius SSS are then gridded into monthly maps at $1^{\circ} \times 1^{\circ}$ resolution. In situ SSS from the Argo network are gridded likewise. SSS discrepancies are computed from the differences in monthly maps between Aquarius and Argo. Additional adjustments to the Aquarius retrievals are included to account for differences in atmospheric models and in SST dependencies of wind model between Aquarius V3 and SMOS RTM. The first adjustment accounts for the change in atmospheric correction in the last version of the Aquarius product (V5) which uses the MPM 92 [4]. The second adjustment accounts for small differences due to the fact that SMOS uses a single layer atmospheric model (driven by surface parameters) based on the MPM 93 [12], while Aquarius V5 uses a multi-layer model based on MPM92. This second adjustment has been estimated using ECMWF atmospheric profiles over the global ocean spread amongst one year (one day every month). The third adjustment accounts for the different SST dependency of $T b_{\text {rough }}$ between Aquarius V3 and SMOS models. We have made a rough estimate by considering the SST dependencies of the first Stokes parameter at $28^{\circ}$ incidence angle and for a mean wind speed of $7 \mathrm{~m} \mathrm{~s}^{-1}$ (Figure 2). For reference, we also report results obtained with Aquarius V5 RTM which uses an empirical adjustment of wind-SST model [5].

\section{E. Simulation of the conditional sampling effect:}

As underlined by Stoffelen [37], 'even for unbiased Gaussian error distribution, computing the mean of y over a fixed bin of $\mathrm{x}$ (bin average) does in general reveal a pseudo-bias that depends on the error characteristics of $x$ '. Actually, in case of uneven numbers of measurements in adjacent bins, the binned average is biased because errors in adjacent bins do not compensate each other. Thus, the mean values of $y$ in fixed bins of $x$ depend on x's error and differ from those that would be obtained with non-erroneous x. In our case, both the ECMWF SST and in situ SSS are noisy, due to imperfect forecast or measurement. We assume a Gaussian uncertainty of $0.6^{\circ} \mathrm{C}$ on SST and of 0.1 on SSS (the impact of the latter is expected to be quite small when comparing it to the 0.6 uncertainty of the SMOS retrieved SSS). The simulation of such pseudo-bias is tricky because we do not know the true $\mathrm{x}$ (here $\mathrm{SST}_{\text {true }}$ and $\mathrm{SSS}_{\text {true }}$ ) values; we only know estimated $\mathrm{x}$ (here $\mathrm{SST}_{\text {obs }}$ and $\mathrm{SSS}_{\mathrm{obs}}$ ) measured with some uncertainty. For simplicity, in the following equations we neglect the in situ SSS errors. Within this approximation, the error on the SMOS retrieved SSS only results from an error on SST, as follows:

$\delta S S S=S S S\left(S S T_{\text {obs }}\right)-S S S\left(S S T_{\text {true }}\right)$

$\delta S S S=-\frac{\partial S S S}{\partial T b}\left(\frac{\partial T b}{\partial S S T}\right)\left(S S T_{\text {obs }}-S S T_{\text {true }}\right)$

Given the partial derivatives of Tb with respect to SSS and SST, at an SST $\sim 0^{\circ} \mathrm{C}$, a $0.6^{\circ} \mathrm{C}$ error on SST creates a bias $\delta S S S$ of about 0.4 .

Such an individual SST-related error can be generalized assuming a Gaussian error distribution (G) on SST and a density of points $\rho\left(\mathrm{SST}_{0}\right)$ to estimate the conditional sampling effect (referred to as CSE hereafter) on the mean SSS in a class of $\mathrm{SST}_{0}$ :

$$
\Delta S S S\left(S S T_{0}\right)=\frac{\int \Delta S S S\left(S S T-S S T_{0}\right) \cdot G\left(S S T-S S T_{0}\right) \cdot \rho(S S T) \cdot d S S T}{\int G\left(S S T-S S T_{0}\right) \cdot \rho(S S T) \cdot d S S T}
$$

The density of points $\rho$ (SST) is derived from the statistical distribution of collocated satellite-in situ data as a function of SST. In the following, the CSE will be similarly estimated and removed from Acard comparisons before adjusting the new dielectric constant parametrization.

This CSE correction is not applied when dealing with monthly SSS maps comparisons because the monthly average significantly reduces SST and SSS noise in each pixel.

\section{RESULTS}

Differences between the co-localized SMOS retrieved SSS and in situ SSS binned averaged as a function of ECMWF SST and in situ SSS (Figure 4a) exhibit positive biases at low SST and negative biases at high SST. These differences follow the same tendency as the ones found by Dinnat et al. [3] (Figure 1), although these authors used an earlier version of SMOS processing and slightly different selection criteria (they used data acquired for wind speed conditions between 3 and $12 \mathrm{~m} \mathrm{~s}^{-1}$ rather than 5 and $9 \mathrm{~m} \mathrm{~s}^{-1}$ in the present study). In warm waters, the observed negative differences are not likely to be explained by vertical stratification effects. While such effects may indeed occur between in situ and satellite salinities in river plumes or in rainy conditions associated with differences in measurement depth [23], most of them should have been filtered out by the filtering criteria and the median average technique described in section II.B. Besides, stratification effects cannot explain differences in high salinity (evaporative) areas, whereas our SSS comparisons exhibit differences for every salinity value. CSE (not shown) could explain about half of the SSS differences observed at the extreme boundaries of the SST range, as shown in Figure 4a.

The differences between Acard retrieved from SMOS observations and calculated using KS model (Figure 3b) qualitatively mirror SMOS SSS differences with in situ SSS from Argo (Figure 3a). Both show positive biases for low SST and negative biases for high SST. Acard differences obtained with the MW model (Figure 3c) have a very different shape, with positive values between $5^{\circ} \mathrm{C}$ and $25^{\circ} \mathrm{C}$. This shape is 
qualitatively similar to the one found by [3] for Aquarius SSS retrieved with MW model (Figure 1).

CSE, as estimated from the error model given in equation (6) assuming an error of $0.6^{\circ} \mathrm{C}$ on SST, explains part of the Acard differences for very low and high ends of the SST range where the distribution of SST is quite uneven (Figure 4d and Figure $5 \mathrm{a}$ and $\mathrm{b}$ ), except in the far edges, and close to (SSS=34, $\mathrm{SST}=28^{\circ} \mathrm{C}$ ) with small negative differences (Figure $5 \mathrm{~b}$ ). We next assess uncertainties in the CSE coming from errors in characterizing SST uncertainties. We estimate the effect for an SST noise varying between 0 and $0.6^{\circ} \mathrm{C}$ and compute its standard deviation STDB (Figure 5c). The CSE is very sensitive to the magnitude of the SST noise only in (SSS, SST) regions with a small number of points. In order to limit as much as possible uncertainties on dielectric constant due to uncertainties in SST noise, the (SSS, SST) pairs with STDB larger than 0.05 have been removed for the following analyses. Similarly, pairs including less than 20 collocated points are removed (Figure 4d).

Using the remaining pairs (Figure 5d), we estimate $\alpha$ in each SST bin, taking as prior the constant $0.00314 \alpha$ value derived by ST (see section $\mathrm{C}$ above). We then carry out a polynomial adjustment of $\alpha$ against SST (Figure 6a) and obtain the so-called $\mathrm{BV}$ parametrization:

$\alpha(\mathrm{T})=\mathrm{PP}(1) * \mathrm{~T}^{3}+\mathrm{PP}(2) * \mathrm{~T}^{2}+\mathrm{PP}(3) * \mathrm{~T}+\mathrm{PP}(4)$

with $\mathrm{PP}=10^{-3 *} * 0.000001749069, \quad 0.001088535951$, $0.038972693320,3.228077425434]$;

As expected, the overall agreement between SMOS retrieved Acard and Acard computed with BV is much better than when using other models (Figure 6b). Over the medium SST range, results when using either KS or BV are quite close (Figure $6 \mathrm{c}$ and Figure 6d).

Independent assessments of the BV parametrization efficiency are next conducted using either the new version of SMOS data or the Aquarius data.

With SMOS updated version (Figure 7), the systematic differences between SMOS SSS and in situ SSS is much reduced, especially in cold waters. For low SST, the difference is up to 1 with $\mathrm{KS}$ and 0.2 with BV. The SST-dependent biases in SSS retrievals are also reduced in the range of moderate temperature $\left(7-30^{\circ} \mathrm{C}\right)$, where differences between SSS retrieved with BV and ISAS SSS are more stable and within less than +/0.05 (black line on Figure 7). The 0.1-0.2 remaining differences that remain below $6^{\circ} \mathrm{C}$ are on the same order as the variations of the monthly systematic differences in this temperature range (not shown), hence possibly linked to other issues than dielectric constant.

With Aquarius V3 reprocessed using BV dielectric constant and MPM92 atmospheric model, the systematic differences are also significantly reduced to within less than $+/-0.1$ (from blue line to black dashed curve in Figure 8). However, Aquarius uses a multilayer atmospheric model MPM92 [4], slightly different from the SMOS monolayer model. The latter [13] was fitted to a multi-layer model using MPM 93 coefficients [12] and standard atmospheric profiles. It depends on surface atmospheric temperature and pressure, leading, at first order, to an apparent SST correlation. Two third of the difference coming from different atmospheric models (difference between dashed black and dashed grey curves on Figure 8) can be explained by the use of a monolayer model approximation, while the rest comes from the difference between [12] and [4] parametrizations. Interestingly, the differences coming from different atmospheric models are almost compensated by the differences coming from wind-SST models (black dashed, grey dashed and black continuous lines). This illustrates the remaining uncertainties in present models and parametrizations as well as compensating effects. The remaining 0.15 peak to peak differences between $7^{\circ} \mathrm{C}$ and $25^{\circ} \mathrm{C}$ are of similar magnitude but of opposite sign than those obtained with Aquarius V5 RTM.

\section{DISCUSSION}

Systematic differences observed between Sea Surface Salinity retrieved from L-Band radiometric measurements and measured in situ, that depend on SST, are investigated. Ideally, SST dependent flaws should be studied independently of the SSS retrieval algorithm. However, to our knowledge, not enough independent information is currently available to do so. Hence, we start from equation (1) and remove the contributions that are not expected to vary with SST or for which we are most confident in their physical modelling. Actually, given the complex geometry of SMOS, building empirical models is difficult as they need to be valid over a wide range of incidence angles $\left(0-60^{\circ}\right)$. We then look at the residuals in SSS error. They can be explained by various error sources: errors in the auxiliary SST used to retrieve the SSS and/or inaccuracies in the SST-dependency of the forward radiative transfer model used, as described previously. The validation of SST fields is a complex issue due to the rapid variation of the temperature near the sea surface and it is out of the scope of this paper to refine estimates of SST errors for existing products. We assume a Gaussian error of $0.6^{\circ} \mathrm{C}$ on ECMWF IFS SST fields based on estimated errors on OSTIA SST as recommended by the ECMWF team (Phil Brown, pers. comm.). In fact, this value is somewhat larger than the standard deviation of the differences between OSTIA and drifting buoys SST $\left(0.4^{\circ} \mathrm{C}\right.$ in 2012) or Argo SST $\left(0.46^{\circ} \mathrm{C}\right.$ in 2013) reported over the global ocean [38]. Nevertheless, the regional variability of this standard deviation is large. For instance, the error when comparing OSTIA SST to Argo SST in the Southern Atlantic is found to be $0.56 \mathrm{~K}$ in 2013 , but drops to $0.33 \mathrm{~K}$ in 2012. Part of these differences could originate from differences in the depth of the measurements, from the fact that the OSTIA system assimilated different sets of satellite temperatures in 2012 and 2013, and also from the different spatio-temporal sampling of drifters and Argo data sets. On the other hand, given that forecasted SST fields could experience a slightly larger error than analyzed SST fields, our $0.6^{\circ} \mathrm{C}$ error estimate appears reasonable. Furthermore, when determining the coefficients of the polynomial fit of the $\alpha(T)$ function, we removed (see above) data points for which the impact of an uncertainty on the SST error is the largest: this certainly minimizes the impact of SST uncertainty on our results.

The absolute calibration of SMOS Tb used in Acard retrieval remains uncertain. Actually, the OTT calibration depends on the dielectric constant model. We have tested the impact of an Acard bias on our dielectric constant parametrization. If instead of KS model, ST parametrization is used in the OTT calibration, SMOS retrieved Acard is decreased by 0.24 . This leads to a 
slight change in $\alpha(\mathrm{T})$ parametrization. However, the change in $\mathrm{Tb}$ is essentially an absolute shift $(0.2 \mathrm{~K}$ at nadir), while its variation with SST remains very similar.

We have also tried to empirically adjust the fresh water relaxation time $\tau$ in equation (4) instead of $\alpha$. This seemed interesting because fresh water parameters are very similar in ST and MW but not KS. It is possible indeed to adjust Acard and $\mathrm{Tb}$ in a very similar manner over the observed range of oceanic SSS and SST (not shown). Nevertheless, it was found that the $\tau$ adjustment degrades the freshwater dielectric constant: the rms difference between simulated Acard and Acard derived from dielectric constants measurements (Table 2 of [30] for frequencies less than $30 \mathrm{GHz}$ ) increases from 0.2 when using MW model to 0.6 with the modified $\tau$-model. On another hand, with BV parametrization, the freshwater dielectric constant remains unchanged and hence consistent with existing laboratory measurements.

$\mathrm{BV}$ parametrization has been adjusted with L-band radiometric measurements. Testing it at higher frequencies would provide another interesting assessment.

When the BV parametrization is applied to the updated version of the SMOS Tbs and to Aquarius Tbs, systematic differences between satellite SSS and in situ SSS are significantly reduced, down to less than 0.2 for SMOS, and within 0.15 for Aquarius in the range of SST between 0 and $30^{\circ} \mathrm{C}$ (Figure 7 and Figure 8 ). SMOS differences are reduced to less than $+/-0.05$ between 8 and $30^{\circ} \mathrm{C}$. These results depend on atmospheric and wind models but differences in both models in Aquarius and SMOS processing almost cancel each other (Figure 8). This underlines that our adjustment of dielectric constant parametrization is slightly dependent on the atmospheric model and wind model used in SMOS processing. However, while a multilayer atmospheric model is expected to be more precise than a monolayer approximated model, the difference between both estimates lies within the uncertainty arising from absorption cross sections, which in turn reflects the one (about 5\%) on laboratory spectroscopic measurements. Orders of magnitude for the resulting uncertainty on $\mathrm{Tb}$ are 0.1 to $0.2 \mathrm{~K}$.

Using BV parametrization, SMOS and Aquarius retrieved salinity have been improved very similarly. Future studies should look at possible interactions between wind effects on sea surface emissivity and dielectric constant model parametrization. The slight positive difference $(\leq 0.2)$ remaining at low SST (Figure 7 and Figure 8), is, given the low signal to noise ratio at low temperature, equivalent to a difference of $0.04 \mathrm{~K}$ in $\mathrm{Tb}$. It may come from multiple origins, like uncertainties in roughness correction in the Southern Ocean or ocean-ice transition effects on the Tbs.

Laboratory measurements are a key to test dielectric constant models in controlled conditions. We have compared $\mathrm{Tb}$ estimated using the BV parametrization with the ones derived with other models, and in particular with the one derived by Zhou et al. [39] (Zhou hereafter) using a parametrization empirically derived from Lang et al. [40] laboratory measurements (Figure 9). The SMOS OTT calibration calculated with KS is the reason why, on average, (Tb-TbKS) obtained with BV is centered on 0 . On another hand, the shift of (Tb-TbKS) between BV, MW and ST is almost independent on the SSS between 30 and 38 unlike the shift between Zhou and the other models. While a constant bias on $\mathrm{Tb}$ may remain following SMOS calibration, there is no reason for this bias to vary with SSS. This behavior will need to be checked in future studies with more extensive laboratory measurements. For SSS equal to 33 and 35 (Figure 9a, b), the relative variation of (TbTbKS) with SST obtained with BV is closer to that obtained with Zhou than to those obtained with ST and MW parametrizations: between $0^{\circ} \mathrm{C}$ and $10^{\circ} \mathrm{C}$ the increase in $\mathrm{Tb}$ is 0.2 to $0.3 \mathrm{~K}$ with Zhou and $\mathrm{BV}$ parametrizations, while it is $0.5 \mathrm{~K}$ with ST and MW parametrizations. Moreover, maximum (TbTbKS) value is at $30^{\circ} \mathrm{C}$ with Zhou and $\mathrm{BV}$ parametrizations while it is around $12^{\circ} \mathrm{C}$ with $\mathrm{MW}$ and $\mathrm{ST}$ parametrizations. For SSS equal to 30 and 38 (Figure 9c,d), which are rather rare and extreme SSS values over the global ocean and, as such, filtered out in our SMOS learning data set (Figure 5d), the SST dependency of (Tb-TbKS) is flatter with BV than with other models, indicating that $\mathrm{BV}$ parametrization is closer to $\mathrm{KS}$ although SMOS Acard used to derive BV parametrization is retrieved independently of KS model. The SST dependence of the dielectric constant is different between ST and BV parametrization due to a non-monotonous temperature variation of $\alpha$ in BV (Figure 6a) while $\alpha$ is constant in ST. For freshwater (Figure 9e), equation 4 is equivalent to equation $3 b$, so that by construction BV is similar to both ST and MW. For freshwater, Zhou parametrization is not applicable anymore as it was empirically fitted to measurements corresponding to SSS between 30 and 38 and very large errors are observed when operating very far away from this range.

\section{CONCLUSION}

We study how to deal with apparent SST dependency of residuals between satellite and co-localized in situ salinity measurements by retaining as much as possible physical basis in the modelling of the various components of the radiative transfer model. The apparent SST dependency is associated to several phenomena. When level 2 data are binned as a function of SST, SST errors can explain part of the apparent dependency at very low and very high SST, but significant differences remain after correcting for this effect. The remaining differences can be significantly minimized by introducing an SST dependency in the salinity term of the static dielectric constant of sea water $(\alpha)$, in the physically based ST dielectric constant model. We propose here a modification along those lines, adapted to SMOS observations. It is complicated to infer imperfections in dielectric constant modelling from SMOS retrieved SSS due to the multiple incidence angles visited by SMOS measurements. Hence, we use the SMOS Acard parameter which provides a synthesized information on the dielectric constant of the observed surface. As far as the SST dependency is concerned, the resulting and newly derived BV dielectric constant is intermediate between KS and ST (or MW). Our parametrization significantly reduces SST dependency of both SMOS and Aquarius retrieved SSS residuals. However, we also show that the relative impact of wind-SST parameterizations and the various atmospheric correction schemes adopted for SMOS and Aquarius are significant sources of uncertainties and various model errors may compensate each other. In particular, we observe that the 
reduction of SST systematic differences obtained with BV dielectric constant is of similar magnitude as the one obtained with Aquarius V5 wind-SST model. But Aquarius V5 windSST model uses an empirical temperature dependency that was fitted to Aquarius measurements while SMOS processing uses a physically based wind-SST model which provides consistent simulations over the wide range of incidence angles sampled by SMOS measurements. Some uncertainties in the new dielectric constant parametrization may remain due to inaccuracies in either the $\mathrm{Tb}$ absolute calibration, or the atmospheric and windinduced emissivity models. This emphasizes the need for more laboratory measurements of sea water dielectric constant, in view of decoupling the various sources of radiometric model deficiencies. Such measurements are needed over a wide range of SSS and SST in order to ensure rigorous adjustments of dielectric constant model parameters. Further assessment or improvement using new laboratory measurements should consider keeping the physics-based formulation by ST that has been shown here to be very efficient.

\section{ACKNOWLEDGMENT}

We thank two anonymous reviewers for constructive remarks about this manuscript. We are indebted to Manuel Arias and Paul Spurgeon for their strong involvement in L2OS processor development, and in particular Acard retrieval chain. We warmly thank Roberto Sabia for his constructive support, and Raffaele Crapolicchio and Patricia De Rosnay for their help about ECMWF IFS fields documentation. We are very grateful to Stéphane Ferron for providing us with a multi-layer atmospheric model allowing multiple tests. We acknowledge CMEMS for providing online near real time ISAS (CMEMSINS-PUM-013-002-ab) products.

\section{REFERENCES}

[1] N. Reul et al., "Sea surface salinity estimates from spaceborne Lband radiometers: An overview of the first decade of observation (2010-2019)," Remote Sensing of Environment, vol. 242, p. 111769 , 2020/06/01/ 2020, doi: https://doi.org/10.1016/j.rse.2020.111769.

[2] N. Vinogradova et al., "Satellite Salinity Observing System: Recent Discoveries and the Way Forward," (in English), Frontiers in Marine Science, Review vol. 6, no. 243, 2019-May-22 2019, doi: 10.3389/fmars.2019.00243.

[3] E. P. Dinnat, D. M. Le Vine, J. Boutin, T. Meissner, and G. Lagerloef, "Remote Sensing of Sea Surface Salinity: Comparison of Satellite and In Situ Observations and Impact of Retrieval Parameters," Remote Sensing, vol. 11, no. 7, p. 750, 2019. [Online]. Available: https://www.mdpi.com/2072-4292/11/7/750.

[4] H. J. Liebe, P. W. Rosenkranz, and G. A. Hufford, "Atmospheric 60-GHz oxygen spectrum: New laboratory measurements and line parameters," Journal of Quantitative Spectroscopy and Radiative Transfer, vol. 48, no. 5, pp. 629-643, 1992/11/01/ 1992, doi: https://doi.org/10.1016/0022-4073(92)90127-P.

[5] T. Meissner, F. J. Wentz, and D. M. Le Vine, "The Salinity Retrieval Algorithms for the NASA Aquarius Version 5 and SMAP Version 3 Releases," Remote Sensing, vol. 10, no. 7, p. 1121, 2018. [Online]. Available: https://www.mdpi.com/2072-4292/10/7/1121.

[6] E. P. Dinnat, J. Boutin, G. Caudal, and J. Etcheto, "Issues concerning the sea emissivity modeling at $\mathrm{L}$ band for retrieving surface salinity," Radio Science, vol. 38, no. 4, 2003, doi: $10.1029 / 2002$ rs002637.

[7] X. Yin, J. Boutin, N. Martin, and P. Spurgeon, "Optimization of LBand Sea Surface Emissivity Models Deduced From SMOS Data,"
IEEE Transactions on Geoscience and Remote Sensing, vol. 50, no. 5, pp. 1414-1426, 2012

[8] L. Klein and C. Swift, "An improved model for the dielectric constant of sea water at microwave frequencies," IEEE Transactions on Antennas and Propagation, vol. 25, no. 1, pp. 104-111, 1977.

[9] S. H. Yueh, "Modeling of wind direction signals in polarimetric sea surface brightness temperatures," IEEE Transactions on Geoscience and Remote Sensing, vol. 35, no. 6, pp. 1400-1418, 1997.

[10] X. Yin, J. Boutin, E. Dinnat, Q. Song, and A. Martin, "Roughness and foam signature on SMOS-MIRAS brightness temperatures: A semi-theoretical approach," Remote Sensing of Environment, vol. 180, pp. 221-233, 2016/07/01/ 2016, doi: https://doi.org/10.1016/j.rse.2016.02.005.

[11] S. Durden and J. Vesecky, "A physical radar cross-section model for a wind-driven sea with swell," IEEE Journal of Oceanic Engineering, vol. 10, no. 4, pp. 445-451, 1985.

[12] H. J. Liebe, G. A. Hufford, and M. G. Cotton, "Propagation modeling of moist air and suspended water/ice particles at frequencies below $1000 \mathrm{GHz}$," In AGARD, November 01, 1993 $1993 . \quad$ [Online]. Available: https://ui.adsabs.harvard.edu/abs/1993apet.agar.....L.

[13] SMOS_Ocean_Expert_Support_Laboratories, "SMOS L2 OS Algorithm Theoretical Baseline Document,", SO-TN-ARG-GS0007, 2014-09-05 2014.

[14] X. Yin, J. Boutin, and P. Spurgeon, "Biases Between Measured and Simulated SMOS Brightness Temperatures Over Ocean: Influence of Sun," IEEE Journal of Selected Topics in Applied Earth Observations and Remote Sensing, vol. 6, no. 3, pp. 1341-1350, 2013.

[15] S. H. Yueh, R. West, W. J. Wilson, F. K. Li, E. G. Njoku, and Y. Rahmat-Samii, "Error sources and feasibility for microwave remote sensing of ocean surface salinity," IEEE Transactions on Geoscience and Remote Sensing, vol. 39, no. 5, pp. 1049-1060, 2001.

[16] P. Waldteufel, J. Vergely, and C. Cot, "A modified cardioid model for Processing multiangular radiometric observations," IEEE Transactions on Geoscience and Remote Sensing, vol. 42, no. 5, pp. 1059-1063, 2004.

[17] D. W. Marquardt, "An Algorithm for Least-Squares Estimation of Nonlinear Parameters," Journal of the Society for Industrial and Applied Mathematics, vol. 11, no. 2, pp. 431-441, 1963, doi: $10.1137 / 0111030$.

[18] R. Oliva et al., "Status of Radio Frequency Interference (RFI) in the $1400-1427 \mathrm{MHz}$ passive band based on six years of SMOS mission," Remote Sensing of Environment, vol. 180, pp. 64-75, 2016/07/01/ 2016, doi: https://doi.org/10.1016/j.rse.2016.01.013.

[19] M. Martín-Neira et al., "SMOS instrument performance and calibration after 6 years in orbit," in 2016 IEEE International Geoscience and Remote Sensing Symposium (IGARSS), 10-15 July 2016 2016, pp. 2040-2042.

[20] M. Ruiz, D. Fraga, and S. Freitas, "SMOS ECMWF PREPROCESSING ", GMVSA 20961/07 V8/10, available on demand, 2013.

[21] C. J. Donlon, M. Martin, J. Stark, J. Roberts-Jones, E. Fiedler, and W. Wimmer, "The Operational Sea Surface Temperature and Sea Ice Analysis (OSTIA) system," Remote Sensing of Environment, vol. 116, pp. 140-158, 2012/01/15/ 2012, doi: https://doi.org/10.1016/j.rse.2010.10.017.

[22] C. L. Gentemann, P. J. Minnett, and B. Ward, "Profiles of ocean surface heating $(\mathrm{POSH})$ : A new model of upper ocean diurnal warming," Journal of Geophysical Research: Oceans, vol. 114, no. C7, 2009, doi: 10.1029/2008jc004825.

[23] J. Boutin et al., "Satellite and In Situ Salinity: Understanding NearSurface Stratification and Subfootprint Variability," Bulletin of the American Meteorological Society, vol. 97, no. 8, pp. 1391-1407, 2016, doi: 10.1175/bams-d-15-00032.1.

[24] F. Gaillard et al., "Sea surface temperature and salinity from French research vessels, 2001-2013," Scientific Data, vol. 2, no. 1, p. 150054, 2015/10/13 2015, doi: 10.1038/sdata.2015.54.

[25] G. Alory et al., "The French contribution to the voluntary observing ships network of sea surface salinity," Deep Sea Research Part I: Oceanographic Research Papers, vol. 105, pp. 1-18, 2015/11/01/ 2015, doi: https://doi.org/10.1016/j.dsr.2015.08.005.

[26] N. Kolodziejczyk, A. Prigent-Mazella, and F. Gaillard. ISAS-15 temperature and salinity gridded fields, doi: 10.17882/52367. 
[27] M. J. Brodzik, B. Billingsley, T. Haran, B. Raup, and M. H. Savoie, "EASE-Grid 2.0: Incremental but Significant Improvements for Earth-Gridded Data Sets," ISPRS International Journal of GeoInformation, vol. 1, no. 1, pp. 32-45, 2012. [Online]. Available: https://www.mdpi.com/2220-9964/1/1/32.

[28] P. J. W. Debye, Polar molecules. New York: The Chemical Catalog Company, Inc. (in English), 1929.

[29] R. Somaraju and J. Trumpf, "Frequency, Temperature and Salinity Variation of the Permittivity of Seawater," IEEE Transactions on Antennas and Propagation, vol. 54, no. 11, pp. 3441-3448, 2006.

[30] T. Meissner and F. J. Wentz, "The complex dielectric constant of pure and sea water from microwave satellite observations," IEEE Transactions on Geoscience and Remote Sensing, vol. 42, no. 9, pp. 1836-1849, 2004

[31] T. Meissner and F. J. Wentz, "The Emissivity of the Ocean Surface Between 6 and $90 \mathrm{GHz}$ Over a Large Range of Wind Speeds and Earth Incidence Angles," IEEE Transactions on Geoscience and Remote Sensing, vol. 50, no. 8, pp. 3004-3026, 2012.

[32] A. Stogryn, H. Bull, K. Rubayi, and S. Iravanvhy, "The microwave dielectric properties of sea and fresh water," GenCorp, Aerojet, Azusa, Ca. 91702, 1995.

[33] W. Ellison et al., "New permittivity measurements of seawater," Radio Science, vol. 33, no. 3, pp. 639-648, 1998.

[34] F. Wentz and T. Meissner, "Amsr Ocean Algorithm (Version 2)," Remote Sens. Syst., Santa Rosa, CA. Available: http://www.remss.com, 1999.

[35] J. Boutin et al., "New SMOS Sea Surface Salinity with reduced systematic errors and improved variability," Remote Sensing of Environment, vol. 214, pp. 115-134, 2018/09/01/ 2018, doi: https://doi.org/10.1016/j.rse.2018.05.022.

[36] F. Gaillard, T. Reynaud, V. Thierry, N. Kolodziejczyk, and K. v. Schuckmann, "In Situ-Based Reanalysis of the Global Ocean Temperature and Salinity with ISAS: Variability of the Heat Content and Steric Height," Journal of Climate, vol. 29, no. 4, pp. 1305-1323, 2016, doi: 10.1175/jcli-d-15-0028.1.

[37] A. Stoffelen, "Toward the true near-surface wind speed: Error modeling and calibration using triple collocation," Journal of Geophysical Research: Oceans, vol. 103, no. C4, pp. 7755-7766, 1998, doi: 10.1029/97jc03180.

[38] E. F. A. McLaren, J. Roberts-Jones, M. Martin, C. Mao, S. Good, "QUID Global Ocean OSTIA Near Real Time Level 4 Sea Surface Temperature Product SST-GLO-SST-L4-NRT-OBSERVATIONS010-001," CMEMS, CMEMS-SST-QUID-010-001, 2019-09-06 2019.

[39] Y. Zhou, R. H. Lang, E. P. Dinnat, and D. M. L. Vine, "L-Band Model Function of the Dielectric Constant of Seawater," IEEE Transactions on Geoscience and Remote Sensing, vol. 55, no. 12, pp. 6964-6974, 2017.

[40] R. Lang, Y. Zhou, C. Utku, and D. Le Vine, "Accurate measurements of the dielectric constant of seawater at L band," Radio Science, vol. 51, no. 1, pp. 2-24, 2016, doi: 10.1002/2015rs005776. 
Jacqueline Boutin received the Ph.D. degree in physical methods in remote sensing from the University Paris VII, Paris, France, in 1990. She is Senior Research Scientist at the Centre National de la Recherche Scientifique (CNRS), deputy director of the Laboratoire d'Océanographie et du ClimatExpérimentation et Approches Numériques (LOCEAN), Paris, France. She has widely studied the validity of remotely-sensed wind speeds and the ocean-atmosphere exchange of $\mathrm{CO}_{2}$ at large scale using both satellite (wind speeds, sea surface temperature, and ocean color) and in situ data (in particular, carbon-interface ocean-atmosphere autonomous drifters, CARIOCA). Since 1999, she is involved in the Soil Moisture and Ocean Salinity mission. She participated in the development of an L-band sea surface emissivity model and in several airborne campaigns (WISE and EuroSTARRS). She coordinates the French SMOS-Ocean team, and she participates to the European Space Agency Expert Support Laboratories that define and validate the processing of SMOS Level 2 measurements for the retrieval of sea surface salinity.

Jean-Luc Vergely received the engineering degree from the Ecole Nationale du Génie des Eaux et de l'Environnement de Strasbourg, Strasbourg, France, in 1988, and the Ph.D. degree in statistics applied to astronomy from Louis Pasteur University, Strasbourg, France, in 1998. He has been responsible for managing cooperative projects in Africa. Since 2002, he is senior research engineer in ACRI-ST company, France.

Emmanuel P. Dinnat (M'12-SM'16) received an advanced studies degree in instrumental methods in astrophysics and spatial applications and the Ph.D. degree in computer science, telecommunications, and electronics from University Pierre and Marie Curie, Paris, France, in 1999 and 2003, respectively. He is currently a Research Scientist with the Center of Excellence in Earth Systems Modeling and Observations, Chapman University, Orange, CA, USA, and the Cryospheric Sciences Laboratory, NASA Goddard Space Flight Center, Greenbelt, MD, USA. He is working on the calibration and validation and algorithm improvements for the Soil Moisture and Ocean Salinity, the Aquarius/SAC-D, and the Soil Moisture Active Passive missions. His latest research focuses on high latitude oceanography and the interactions between the cryosphere and oceans. His research interests include active and passive microwave remote sensing, sea surface salinity, scattering from rough surfaces, atmospheric radiative transfer, and numerical simulations.

Philippe Waldteufel received the degree from the École Polytechnique, Palaiseau, France, in 1962, and a Doctorat d'État from the Université de Paris, Paris, France, in 1970. He is a Senior Scientist Emeritus at the Centre National de la
Recherche Scientifique. His main scientific interests have been ionospheric and thermospheric physics, radar meteorology, radiowave propagation, macroeconomics, and finally microwave radiometry. He has also served as Director of the Institut de Physique du Globe de Clermont-Ferrand, Deputy Director in the French Weather Service Research Department, and Director for Science in the French Research Ministry. He cosigned to the original Soil Moisture and Ocean Salinity proposal in 1997.

Francesco D'Amico received a M. Sc. in Telecommunications, specialty passive and active remote sensing, from the University of Pisa, Pisa, Italy, in 2015. From 2016 to 2019, he worked at LOCEAN as engineer on SMOS algorithms validation and development. He is now working on SMOS L2OS processor with Argans company.

Nicolas Reul is currently an Oceanographer with the Laboratory for Ocean Physics and Satellite Remote Sensing (LOPS), IFREMER, University of Western Brittany, Brest, France. Since 2000, he has been leading research and development activities around the satellite remote sensing of sea surface salinity from low-frequency microwave radiometers. He has been a Co-Principal Investigator of the ESA/Soil Moisture and Ocean Salinity (SMOS) Mission since 2014, leading the Expert Support Laboratories dedicated to the ocean side of the mission for ESA and for the CNES/Centre Aval de Traitement des données SMOS (CATDS), the French ground segment for the SMOS Level 3 and 4 data. His research interests include ocean surface measurements from space in extreme wind conditions (Hurricanes), air-sea interactions, sea surface waves, fluid mechanics, and electromagnetism.

Alexandre Supply received the M.S. degree in 'Sciences De l'Univers, de l'Environnement et de l'Écologie', specialty 'Océan, Atmosphère, Climat et Observations Spatiales', of University Pierre and Marie Curie, Paris, France, in 2014. From 2015 to 2017, he worked as remote sensing engineer at LOCEAN, Paris on the influence of rainfall on SMOS SSS. Since 2018, he is PhD student at LOCEAN, studying the impact of fresh water on satellite salinity.

Clovis Thouvenin-Masson received the M.S. degree (specialty Physics and Monitoring of Environment) from the University of Toulon, and a Seatech engineer diploma, Toulon, France, in 2016. Since then, his main focus is on the analysis of satellite observations over the ocean. Since 2018, he is research engineer at LOCEAN. 


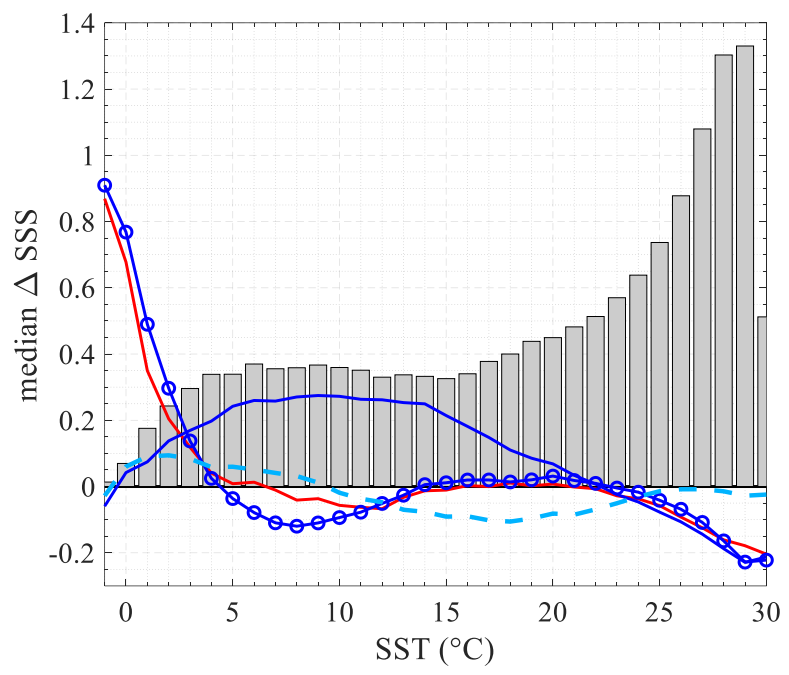

Figure 1: Median of satellite SSS minus Argo SSS differences, binned as a function of Argo SST. SSS data are obtained from Aquarius Tb and (i) Aquarius V3 models (plain blue line), (ii) Aquarius V3 models except for KS [8] dielectric constant and MPM92 [4] atmospheric model (blue circle line), (iii) Aquarius V5 models (dashed light blue line), and finally (iv) from SMOS Tb and SMOS direct models (red; see details in [3]). Number of points (arbitrary scale) are shown as grey bars.

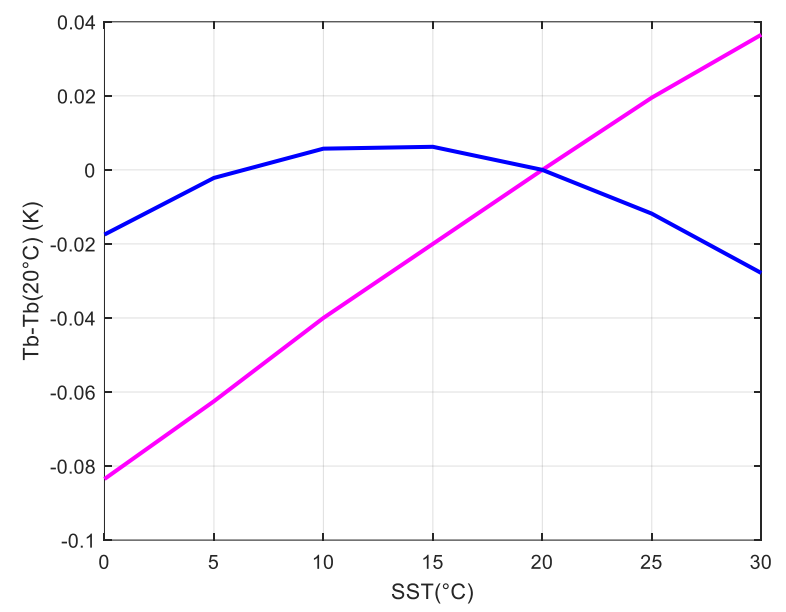

Figure 2: SST dependency of roughness induced Tb signal at a wind speed of $7 \mathrm{~m} \cdot \mathrm{s}^{-1}$ and a SSS of 36, as simulated with the wind models used in Aquarius V3 (blue) and SMOS (magenta) retrievals. The y-axis reports the difference in modelled Tb at the temperature reported on the $x$ axis minus the modelled $\mathrm{Tb}$ at $20^{\circ} \mathrm{C}$. 

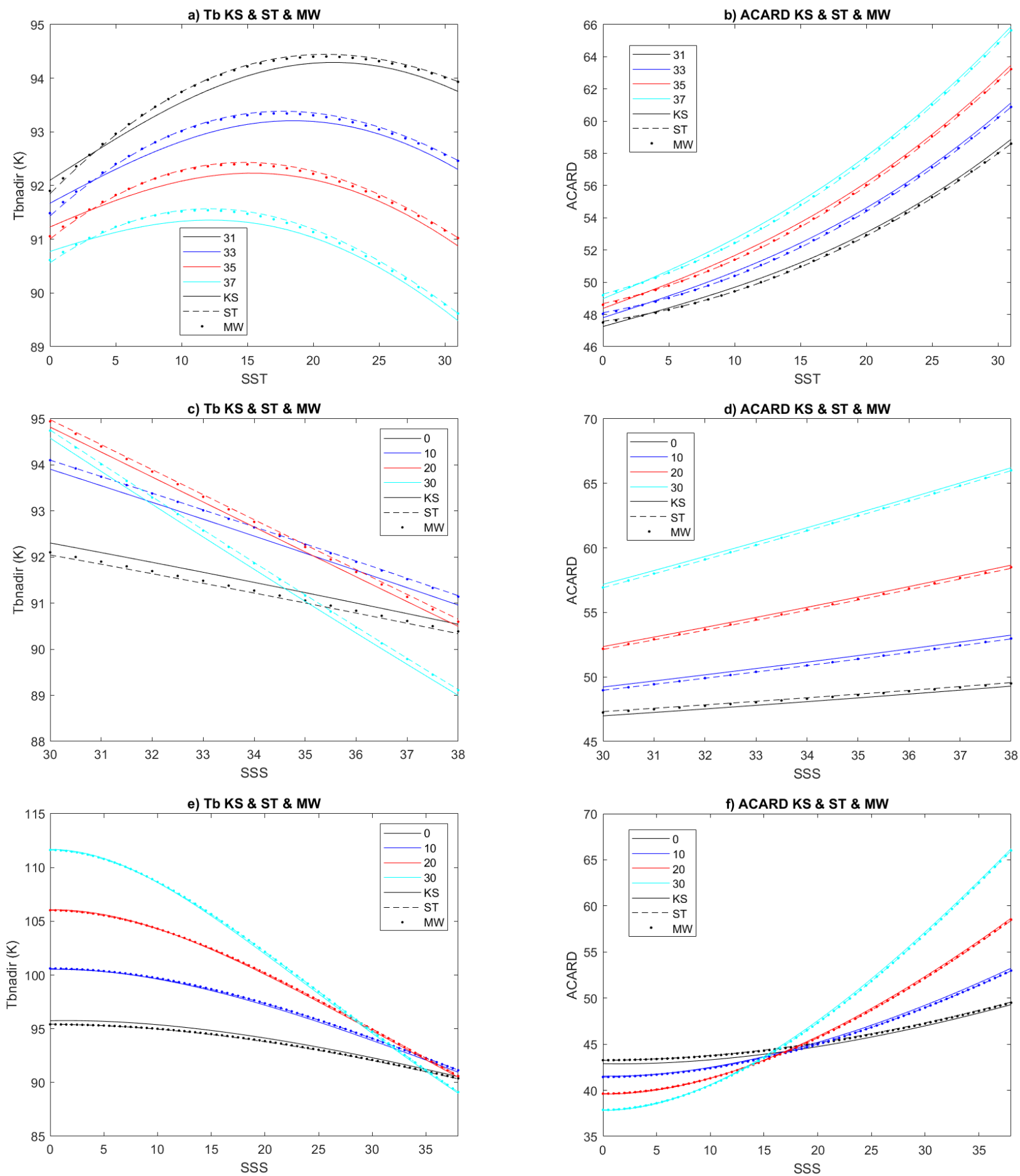

Figure 3: Tb at nadir ( $a, c, e)$ and pseudo dielectric constant Acard $(b, d, f)$ plotted as $(a, b)$ a function of SST, for various SSS values (in color), $(c, d, e, f)$ a function of SSS for various SST values (in color) and $(c, d)$ oceanic ranges of SSS and (e,f) the whole range of SSS, including fresh water. Tb and Acard are simulated with Klein and Swift (1977) (plain line), Meissner and Wentz (2012) (dotted line) and Somaraju and Trumpf (2006) (dashed line) dielectric constant models. 

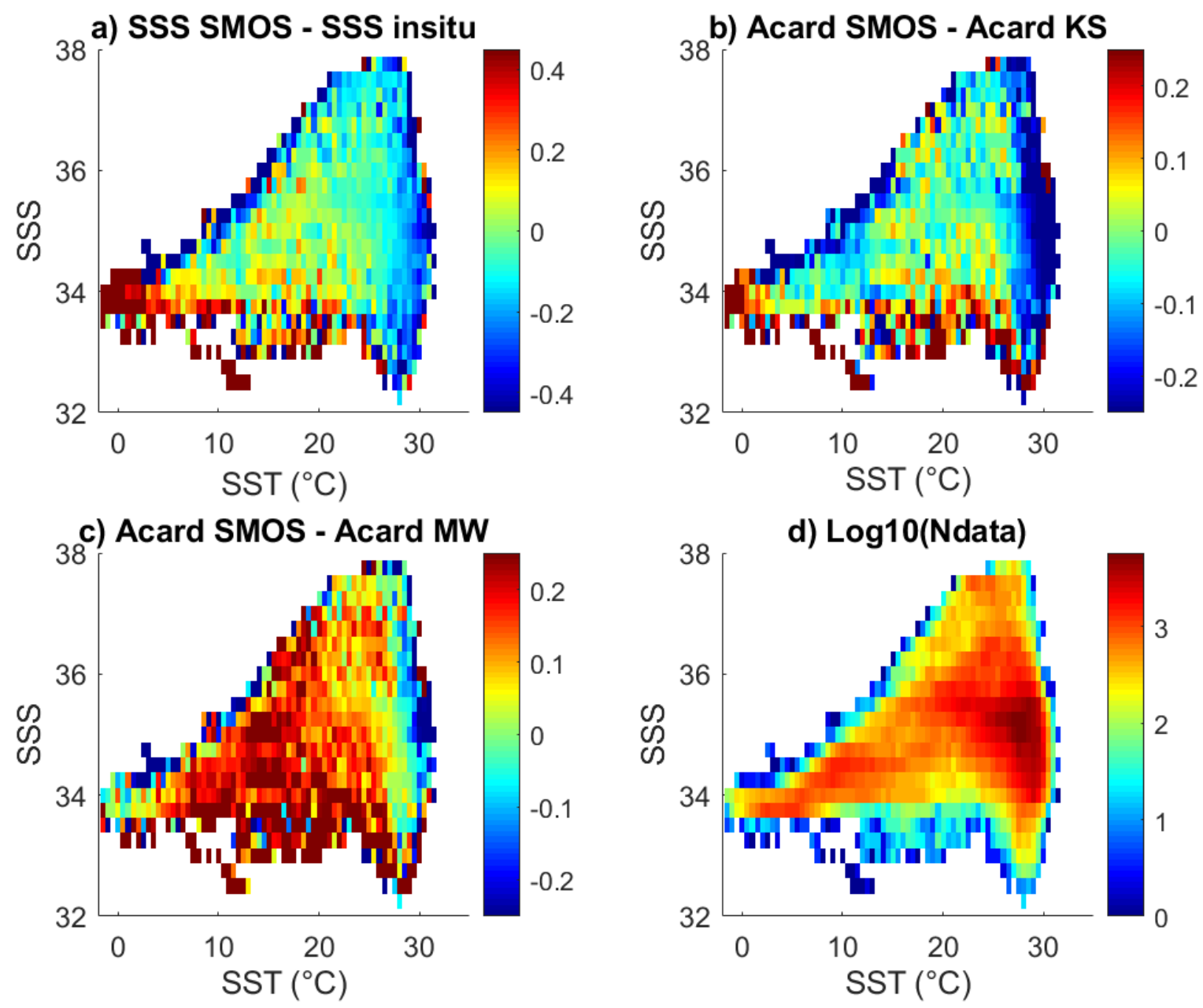

Figure 4: a) SMOS SSS minus in situ SSS; b) SMOS Acard minus Acard estimated using Klein and Swift (1977) dielectric constant model; c) SMOS Acard minus Acard estimated using Meissner and Wentz (2012) dielectric constant model; d) Number of collocated points. 

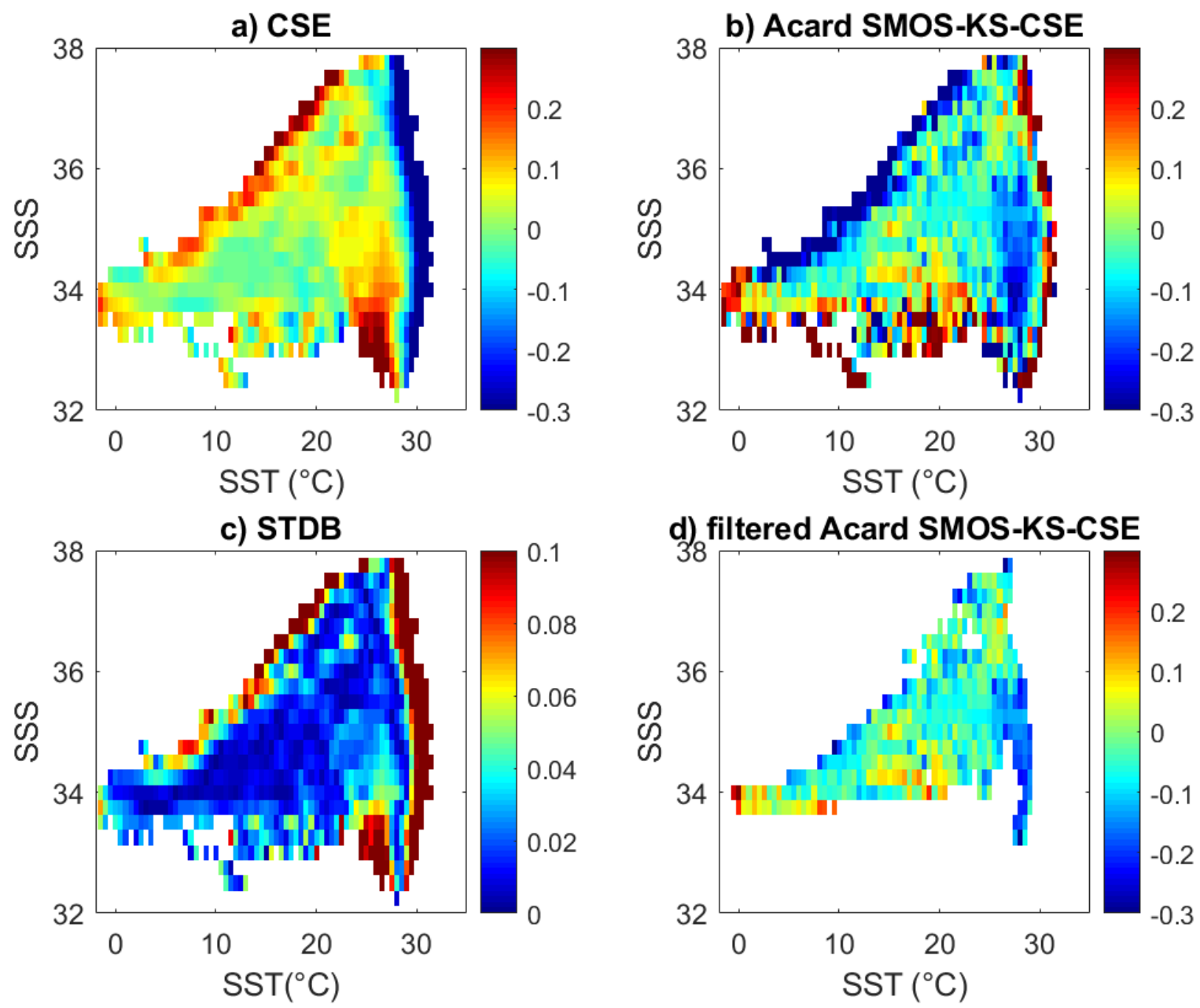

Figure 5: Simulations of conditional sampling effect on SMOS Acard comparisons shown on Figure 4b. a) SSS apparent difference due to a noise of $0.6^{\circ} \mathrm{C}$ on SST with the number of measurements of Figure 4d; b) SMOS Acard minus Acard estimated with (KS) model corrected for the CSE shown in panel a); c) STDB (Standard deviation of the SSS apparent differences simulated for an SST noise varying from 0 to $0.6^{\circ} \mathrm{C}$ ); d) Acard values after filtering out STDB larger than 0.05 and number of collocated points (Figure 4d) less than 20: these remaining values are those used for determining $B V$ parametrization. 

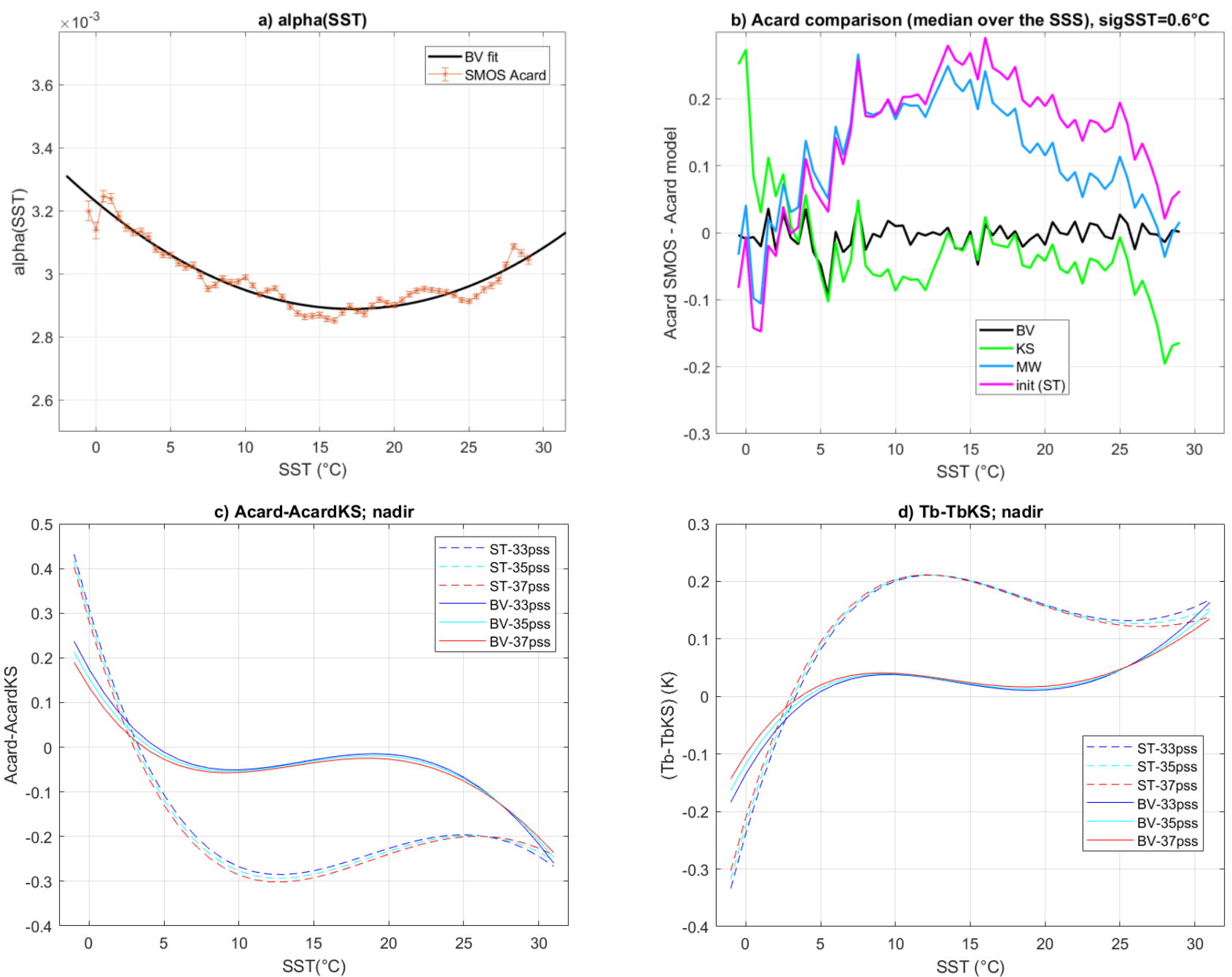

Figure 6:Adjustment of $\alpha$ as a function of SST. a) $\alpha$ derived from SMOS ACARD in $1{ }^{\circ}$ C SST bins (orange crosses) and a polynomial fit to SST used in BV parametrization (black curve). b) SMOS Acard minus Acard simulated with BV (black), KS (green), MW(blue), ST (magenta) dielectric constant; $c$ ) Acard simulated with ST (dashed line) and BV (plain line) parametrizations minus Acard simulated with KS model; d) Tb simulated with ST(dashed line) and BV (plain line) parametrizations minus Tb simulated with KS model (nadir). 


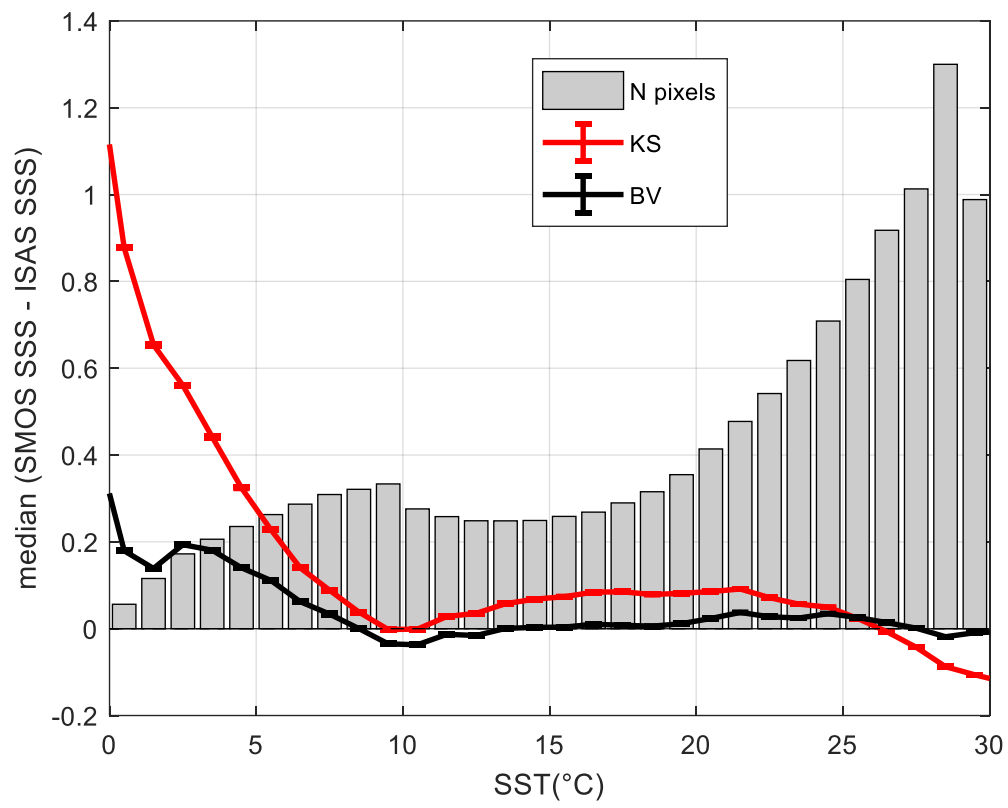

Figure 7: SMOS SSS minus ISAS SSS binned as a function of ISAS SST, when SMOS SSS are retrieved using KS (red) or BV (black) dielectric constant parametrisation. Number of points (arbitrary unit) are shown as grey bars.

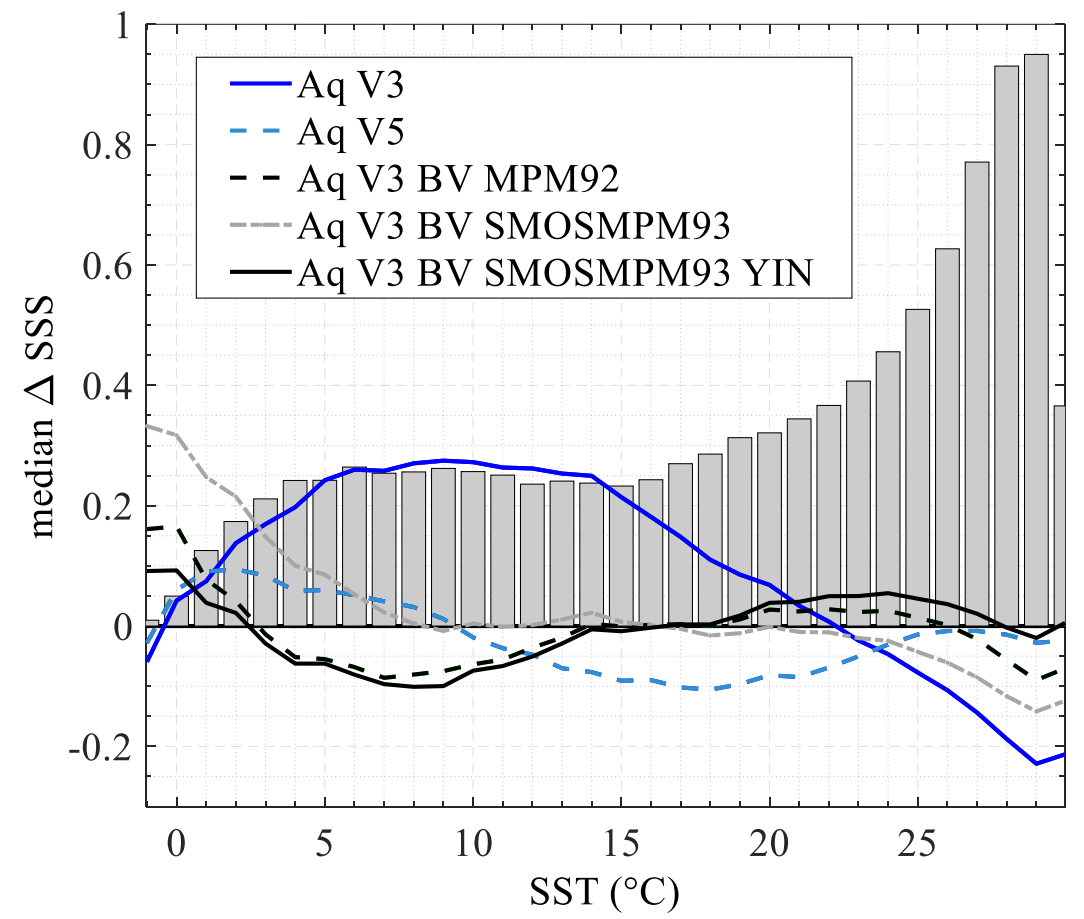

Figure 8: Aquarius SSS minus Argo SSS as a function of Argo SST. Aquarius SSS are retrieved with various options: (blue) Aquarius V3 models except for MW dielectric constant and MPM92 atmospheric model; (black dashed) Aquarius V3 models except for BV dielectric constant and MPM92 atmospheric model; (grey) Aquarius V3 models except for BV dielectric constant plus an adjustment to the SMOS MPM93 atmospheric model; (black) Aquarius V3 models except for BV dielectric constant plus adjustments to the SMOS MPM93 atmospheric model and to SMOS roughness model; (blue dashed) Aquarius V5 models: MW dielectric constant, MPM92 atmospheric model and empirical SST dependency in roughness model. Number of points (arbitrary scale) are shown as grey bars. 

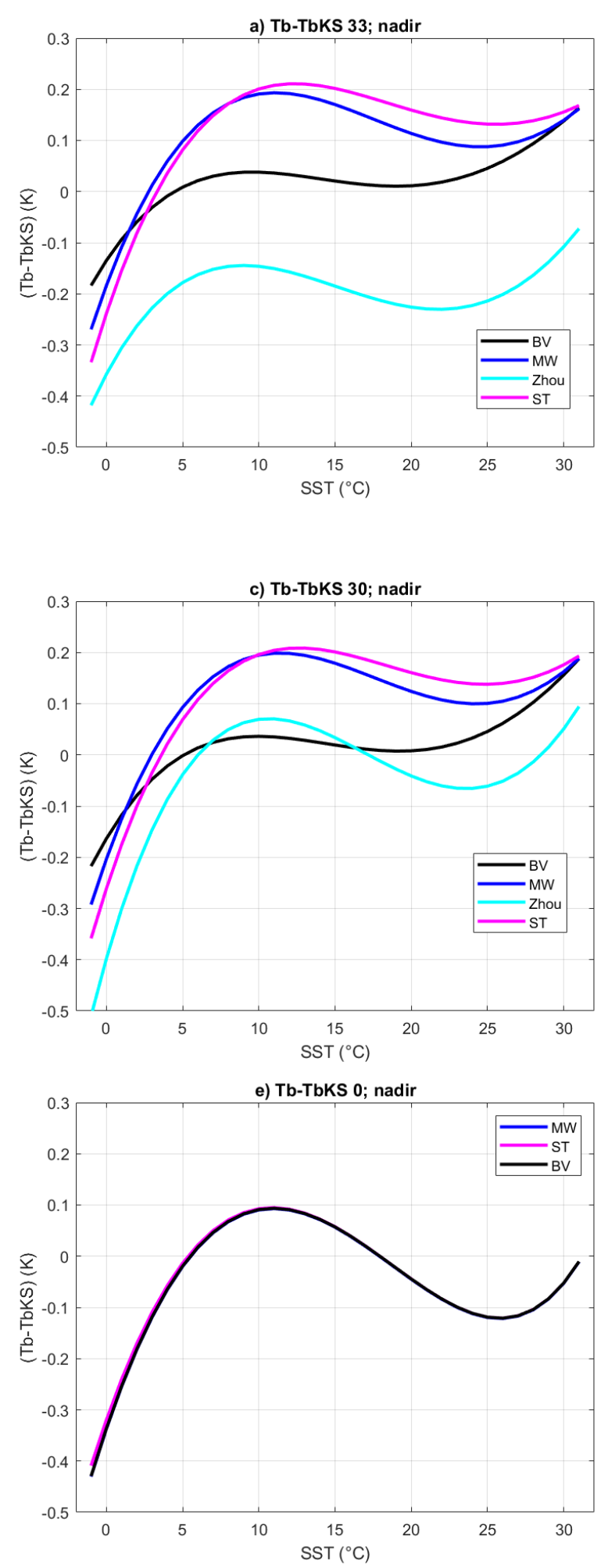
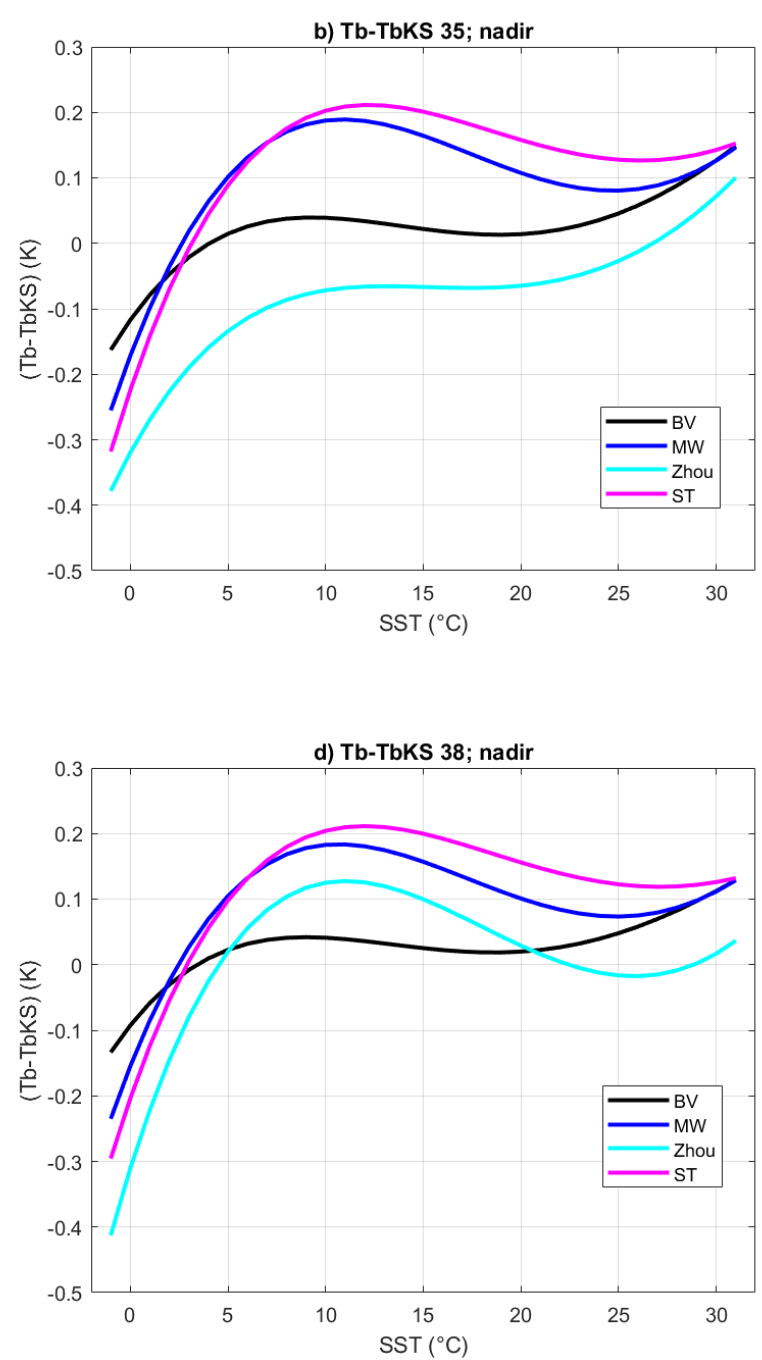

Figure 9: Difference between nadir Tb derived with BV (black), MW(blue), Zhou (cyan) and ST (magenta) parametrizations and Tb derived with KS parametrization as a function of SST for SSS equal to a) 33, b) 35, c) 30, d) 38, e) 0 (fresh water); since fresh water parameters are almost the same for ST, MW and BV the three curves are superimposed here. Zhou (out of scale, differences up to -80K) is not valid anymore as it was fitted to laboratory measurements performed for SSS between 30 and 38. 